\title{
PENGARUH PURSED LIP BREATHING DAN MENIUP BALON TERHADAP KEKUATAN OTOT PERNAPASAN, SATURASI OKSIGEN DAN RESPIRATORY RATE PADA PASIEN PPOK
}

\author{
The Effect Of Pursed Lip Breathing And Balloon Blowing On The Strength Of \\ Respiratory Muscle, Oxygen Saturation And Respiratory Rate In COPD Patients \\ Junaidin', Yuliana Syam², Andi Masyitha Irwan² \\ ${ }^{1}$ Mahasiswa Magister Ilmu Keperawatan Fakultas Keperawatan Universitas Hasanuddin Makassar \\ ${ }^{2}$ Dosen Magister Ilmu Keperawatan Fakultas Keperawatan Universitas Hasanuddin Makassar \\ e-mail: junaidinlaode09@gmail.com
}

\begin{abstract}
ABSTRAK
Masalah : Penyakit Paru Obstruksi Kronik (PPOK) merupakan sej umlah gangguan yang mempengaruhi pergerakan udara dari dan keluar paru. Hal ini disebabkan karena terjadinya kelemahan otot pernapasan dan obstruksi, sehingga terjadi peningkatan resistensi aliran udara, hiperinflasi pulmoner dan ketidakseimbangan ventilasi dan perfusi yang dapat menyebabkan penurunan kadar saturasi oksigen. Terdapat beberapa penanganan pada pasien PPOK salah satunya penanganan secara non farmakologis (program latihan) salah satunya program rehabilitasi, program ini terdiri dari pursed lip brething meniup balon. Tujuan : untuk mengetahui pengaruh latihan pursed lip breathing dan meniup balon terhadap peningkatan kekuatan otot pernapasan, respiratory rate dan peningkatan saturasi oksigen pada pasien penyakit paru obstruksi kronis. Metode : Database yang digunakan dalam pembuatan literatur review ini adalah PubMed, Google Scholar, Proquest, Science direct dan Wiley. Hasil : Terdapat 112 artikel yang diidentifikasi dan dipublikasikan dari tahun 2012-2018. Dari 109 artikel 7 artikel yang memenuhi kriteria inklusi. Beberapa hasil penelitian menunjukkan bahwa pursed lip breathing dapat memperbaiki kekuatan otot pernapasan, saturasi oksigen dan menurunkan frekuensi pernapasan, begitu pula dengan meniup balon. Kesimpulan : Untuk menghindari gangguan vital pada pasien PPOK akibat terganggunya ventilasi pada pasien PPOK dapat pula dilakukan dengan program latihan, salah satunya yaitu dengan cara rehabilitasi yang terdiri atas pursed lip breathing dan meniup balon hal ini dapat meningkatkan kekuatan otot pernapasan, saturasi oksigen dan menurunkan frekuensi pernapasan.
\end{abstract}

Kata Kunci : Pursed lip breathing, meniup balon, otot pernapasan, saturasi oksigen, respiratory rate

\begin{abstract}
ABSTRACK
Problem : Chronic Obstructive Pulmonary Disease (COPD) is a number of disorders that affect the movement of air from and out of the lungs. This is caused by the occurrence of respiratory muscle weakness and obstruction, resulting in increased resistance to airflow, pulmonary hyperinflation and an imbalance of ventilation and perfusion which can cause a decrease in oxygen saturation. There are several treatments for COPD patients, one of them is non-pharmacological treatment (training program), one of them is a rehabilitation program, this program consists of pursed lip brething blowing balloons. Objective: to determine the effect of exercise pursed lip breathing and balloon blowing on increased respiratory muscle strength, respiratory rate and increased oxygen saturation in patients with chronic obstructive pulmonary disease. Methods: The database used in the making of this review literature is PubMed, Google Scholar, Proquest, Science direct and Wiley.
\end{abstract}


Results: There were 112 articles identified and published from 2012-2018. Of 109 articles 7 articles that met the inclusion criteria. Some research results show that pursed lip breathing can improve respiratory muscle strength, oxygen saturation and reduce breathing frequency, as well as blowing balloons. Conclusion: To avoid vital disorders in COPD patients due to disruption of ventilation in COPD patients can also be done with an exercise program, one of which is by means of rehabilitation consisting of pursed lip breathing and blowing balloons this can increase respiratory muscle strength, oxygen saturation and reduce frequency Respiratory.

Keywords: Pursed lip breathing, balloon blowing, respiratory muscles, oxygen saturation, respiratory rate

\section{PENDAHULUAN}

Penyakit Paru Obstruksi Kronik (PPOK) merupakan sejumlah gangguan yang mempengaruhi pergerakan udara dari dan keluar paru, hal ini dapat mengakibatkan hipoksemia dan hiperkapnia karena terjadinya kelemahan otot pernapasan dan obstruksi sehingga akan meningkatkan resistensi aliran udara, hiperinflasi pulmoner dan ketidak seimbangan ventilasi dan perfusi. Salah satu manifestasi klinis yang diperlihatkan adalah dyspnea sehingga dapat menyebabkan penurunan kadar saturasi oksigen (LeMone, Priscilia, et al, 2016). Prevalensi penyakit ini bervariasi diseluruh dunia yaitu didua belas negara di Asia terdapat sebesar $6.3 \%$ (Regional COPD Working Group, 2015), sedangakan di Amerika Serikat PPOK merupakan penyebab utama kematian ketiga (American Lung association, 2015). Dari hasil Riset Kesehatan Dasar (2013), menunjukkan bahwa di Indonesia terdapat 4,8 juta pasien PPOK dengan prevalensi sebesar 5,6 \%. PPOK di Sulawesi Selatan merupakan penyebab kematian pertama untuk penyakit tidak menular berbasis rumah sakit rawat inap yang berjumlah 43 kasus pada tahun 2016 (Profil dinas kesehatan Provinsi Sulawesi Selatan, 2016). Angka mortalitas penyakit ini semakin meningkat (Windrasmara, 2012). Diperkirakan tahun 2030, PPOK merupakan penyebab kematian utama di seluruh dunia (WHO, 2015). Prevalensi kejadian PPOK di dunia rata-rata berkisar 3-11\% (GOLD, 2015). Dengan demikian hal ini sangat membutuhkan penanganan medis yang serius baik secara farmakologi maupun non farmakologi.

Salah satu penanganan secara nonfarmakologis pada PPOK yaitu dengan latihan rehabilitasi diantaranya pursed lip brething dan meniup balon (GOLD, 2017). PPOK bisa menjadi rumit dan membutuhkan waktu penyembuhan yang lama jika tidak dilakukan perawatan dan latihan yang baik. Manajemen perawatan PPOK berfokus memperbaiki fungsi paru, mencegah kerusakan, dan meningkatkan kualitas hidup (C.P. Engstrom, et al 2001). Perawatan secara nonformakologi dengan melakukan latihan pursed lip breathing dan meniup balon pada pasien PPOK secara spesifik tehnik ini dapat memperbaiki pengembangan paru lebih optimal dan mencegah kelelahan otot pernapasan, sehingga penderita PPOK dapat mencapai ventilasi yang lebih terkontrol, efisien dan mengurangi kerja nafas (Smaltzer \& Bare, 2013).

Selain itu terdapat juga beberapa latihan rehabilitasi yang dapat mempengaruhi perbaikan paru dan ventilasi pada pasien PPOK diantaranya tekhnik nafas dalam, latihan pernapasan diafragmatik, latihan rekondisi (aerobic dan yoga), latihan posisi tubuh, endurance exercise (ergocycle dan treadmil) dan terapi fisik dada (GOLD, 2017). Dalam praktek klinis, tehnik tersebut dapat memperbaiki pengembangan paru, mencegah kelelahan otot pernapasan dan mengurangi kerja nafas. Namun tehnik ini membutuhkan instruktur dan dianggap repot dalam pelaksanaannya terutama 
latihan rekondasi, latihan posisi tubuh endurance exercise (ergocycle dan treadmil) dan terapi fisik dada (GOLD, 2017). Tujuan dari studi literatur ini adalah untuk mengidentifikasi pengaruh purshed lip breathing dan meniup balon terhadap kekuatan otot pernapasan,peningkatan saturasi oksigen dan respiratory rate pada pasien PPOK.

\section{METODE}

\section{Sumber Data}

Pencarian sistematis studi literatur ini melalui penelusuran hasil publikasi ilmiah dengan rentang tahun 2010-2018 dala bahasa inggris dengan menggunakan database Pubmed, Science Direct, Google Scholar dan Cochrane berdasarkan teknik pencariaan PICOT Dalam studi literatur ini, kata kunci PICOT yang digunakan adalah P (COPD “OR"Chronic obstrutif pulmonary disease), I (Purshed lip breathing) \& (blowing balloons), C (not blowing balloons),(not purshed lip breathing) O (respiratory muscles), (Oxygen saturation), (Respiratory rate) dan T (-).

Pencarian dilakukan pada 12 Desember 2017, dan diperbarui kembali pada bulan Juli 2018. Strategi pencarian ini diesuaikan pada setiap data base. Sebuah pencarian manual referensi dalam artikel yang dipilih juga dilakukan untuk mengidentifikasi studi tambahan.

Seleksi Study

Dalam melakukan ulasan jurnal dari beberapa jurnal maka dilakukan seleksi jurnal untuk dimasukan dalam kriteria yang ditentukan dan kemudian membaca teks lengkap dan abstrak yang memenuhi syarat seleksi dalam tahap awal. Jurnal duplikat dan jurnal yang berbentuk lietratur review akan dikeluarkan. Pada tahap setelah itu akan memastikan jurnal yang membahas efek intervensi adalah kekuatan otot pernapasan, respiratory rate dan saturasi oksigen pada pasien dewasa adalah efek utama dari jurnal tersebut.

Studi empiris yang menggambarkan praktik pursed lip breathing dan meniup balon untuk mengukur kekuatan otot pernapasan, respiratory rate dan saturasi oksigen untuk mengurangi sesak napas dan meningkatkan saturasi oksigen dalam aktivitas sehari-hari dimana subjek penelitian adalah pasien dewasa dan lansia sampai 65 tahun. Studi berfokus pada pasien yang menderita PPOK.

\section{Ekstraksi Data dan Penilaian Kualitas}

Untuk setiap studi, data tentang karakteristik penelitian diekstraksi. Data dikumpulkan dengan jenis intervensi, efek intervensi, jenis balon pada intervensi meniup balon, frekuensi pada saat intervensi, durasi kedua intervensi, dan efektivitas. Data dikumpulkan berupa data demografi dan klinis sampel (diagnosis utama, dan fungsional).

Desain penelitian yang dirandomisasi termasuk dalam tinjauan sistematis ini, dalam pelakasanaannya ada yang mengunakan kelompok kontrol dan satu group pre post test desain. Pengukuran dalam penelitian beberapa artikel review terdiri atas pre intervensi dan post intervensi, dan adapula yang menggunakan kuisioner untuk melihat ADL pasien. Setiap hasil intervensi ditinjau setelah intervensi penuh dari beberapa minggu.

\section{Sintesis dan Analisa Data}

Mengingat heterogenitas pelaporan dan desain studi yang disertakan,pendekatan deskriptif digunakan untuk meringkas karakteristik penelitian dan hasil. Artikel yang masuk dikategorikan menjadi dua sesuai kedua intervensi pada penulisan ini, tujuan intervensi ini adalah untuk melihat perkembangan otot napas, respiratory rate dan saturasi oksigen setelah intervensi dibandingkan sebelum intervensi. Tidak ada penyatuan statistik yang dilakukan.

\section{HASIL}

Berdasarkan hasil pencarian literatur maka didapatkan 112 artikel, langkah selanjutnya akan dilakukan seleksi kriteria artikel. Adapun kriteria inklusi pada pencarian artikel ini adalah : pemberian intervensi pada responden dewasa, 
intervensi yang terdapat pada artikel adalah pursed lip breathing dan meniup balon. Kekuatan otot napas, respiratory rate dan saturasi oksigen termasuk dalam hasil utama pada artikel tersebut. Sedangkan kriteria ekslusinya adalah artikel kajian teoritis atau review, artikel yang menggunakan responden anak, responden dalam artikelnya bukan pasien PPOK.

Dalam jumlah literatur 112 artikel ini belum dilakukannya adanya seleksi judul dan abstrak, namun setelah dilakukan penyeleksian judul dan abstrak dari duplikat maka hanya terdapat 74 artikel tambah 3 pencarian primer, maka menjadi 77 artikel. Selanjutnya 58 artikel tereliminir karena tidak berhubungan dengan efek intervensi yang diinginkan, merupakan makalah diskusi atau tidak memenuhi kriteria inklusi, maka tersisa 19 artikel. Pada tahap berikutnya 19 artikel teks lengkap disaring, maka hanya didapatkan 7 artikel, karena 4 artikel tidak memenuhi kriteria desain kajian (teoritis/review), 2 artikel tidak memenuhi kriteria responden responden anak dan 6 artikel tidak memenuhi ktiteria intervensi seperti kekuatan otot napas, respiratory rate dan saturasi oksigen. 7 artikel dimasukan dalam tinjauan sistematis ini, 4 artikel meniup balon dan 3 artikel pursed lip breathing.

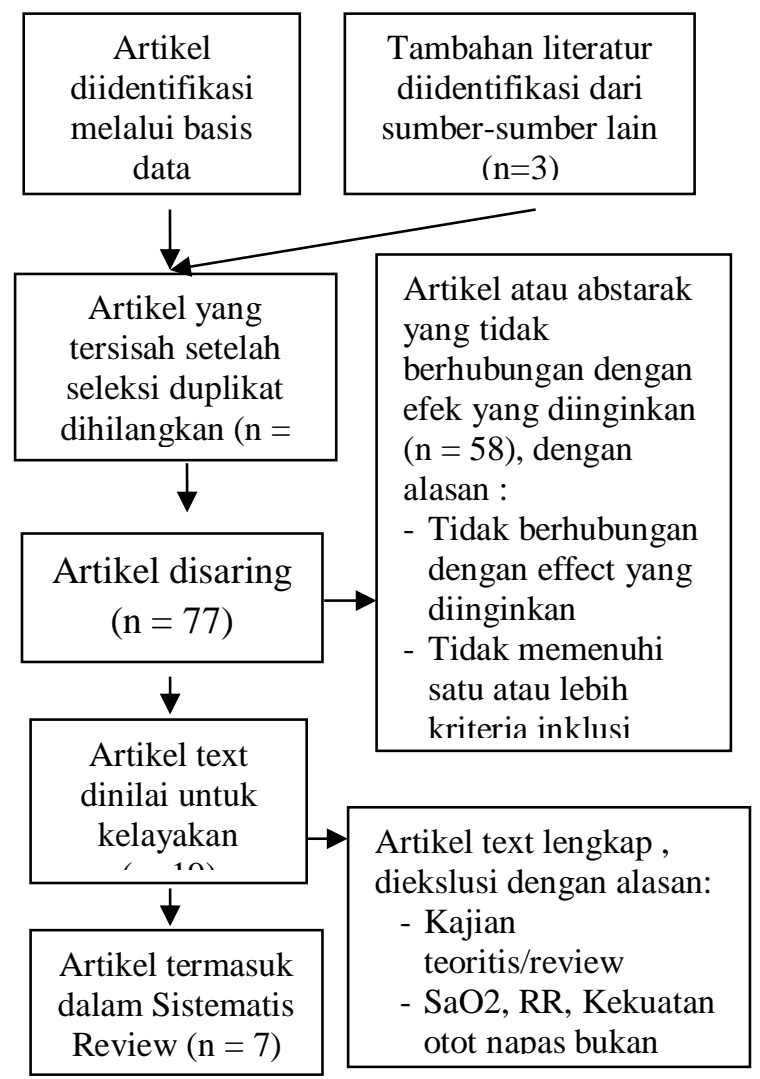

Gambar 1: Diagram Pencarian Literatur Penelitian-penelitian dalam pencarian artikel ini mengidentifikasi pengaruh purshed lip breathing dan meniup balon terhadap kekuatan otot pernapasan, saturasi oksigen dan respiratory rate. Untuk pencarian data base dengan cara: intervensi purshed lip breathing menggunakan "the effectiveness of pursed lip breathing " AND "oxygen saturation"AND "COPD. the effectiveness of blowing balloons" AND "oxygen saturation"AND "respiratory muscles" AND "Respiratory rate" AND "COPD"OR "Chronic obstructif pulmonary disease". Pubmed intervensi blowing balloons menggunakan the effectiveness of blowing balloons" AND "oxygen saturation"AND "COPD. the effectiveness of blowing balloons" AND "oxygen saturation"AND "respiratory muscles" AND "Respiratory rate" AND "COPD"OR "Chronic obstrutif pulmonary disease".

\section{Kualitas Studi}

Hasil penilaian kualitas empat artikel meniup balon, dua artikel merupakan studi kontrol dan 2 studi merupakan studi pre post test desain. studi memiliki ukuran sampel yang kecil. 3 artikel memiliki ukuran sampel yang kecil dimana kriteria inkuksi dan ekslusinya tidak jelas, namun menjelaskan sampelnya adalah PPOK perokok. Satu artikel dengan sampel yang cukup. Penelitiaan tidak memiliki tindak lanjut.

Untuk penilaian kualitas tiga artikel pursed lip brathing merupakan satu artikel merupakan studi kontrol dan dua artikel merupakan studi pre post desain,satu artikel dengan sampel yang kecil, sampel dengan PPOK perokok, satu artikel dengan sampel yang cukup >65 tahun, sedangkan satu artikel dengan jumlah sampel yang tidak jelas baik jumlahnya ataupun kriteria 
inklusi dan ekslusinya. Memiliki tindak lanjut yang jelas untuk penelitian selanjutnya.

\section{Karakteristik Studi}

Dari beberapa artikel menunjukan karakteristik studi sebagai berikut : dua artikel merupakan studi kontrol, satu studi merupakan studi longitudinal, sedangkan 4 artikel merupakan studi pre post test desain. Jumlah sampel pada studi ini bervariasi dari 20 responden bahkan sampai 60 responden, usia sampel bervariasi dari yang muda berusia 20 tahun, usia 12 tahun, usia dewasa sampai usia lansia diatas 65 tahun. Pengambilan data primer pada responden dilakukan diempat tempat yaitu: di Rumah sakit, Pusat Rehabilitasi, di sekolah dan dirumahrumah responden.

Dari 7 studi yang direview pada penulisan ini terdapat berbagai kebijakan dalam pengambilan data pada responden, satu studi mendiskualifikasi jika responden mengalami sakit ditengah penelitian berlangsung pada responden yang mengalami penyakit kronis, satu studi memberikan waktu istrahat pada responden jika responden mengalami kelelahan atau sakit jantung saat penelitian berlangsung yaitu pada responden lansia, dan lima studi yang lain penelitian berjalan dengan baik tanpa ada hambatan pada responden dengan fungsi tubuh dan kognitif yang baik. Semua penelitian difokuskan pada kekuatan otot napas, respiratory rate dan saturasi oksigen sebagai ukuran hasil.

\section{Karakteristik Metode Pursed Lip Breathing dan Meniup Balon}

Studi yang dilakukan oleh Hyun Ju Jun, et al (2015) bertujuan semata-mata untuk meningkatkan fungsi paru, difokuskan pada kekuatan otot napas, respiratori rate dan peningkatan saturasi oksigen atau mengetahui analisis metode terapi non farmakologi terhadap peningkatan fungsi paru, hal tersebut juga difokuskan untuk menilai efek dari rehabilitasi paru termasuk fokus efek terapi ini yaitu VC, ERV, Irv,
FVC, FEV1, FEV1 / FVC dan PEF. Sudut pandang dari semua studi yang sesuai kriteria inklusi bahwa pursed lip breathing dan meniup balon sangat baik untuk dilakukan pada panderita PPOK dimana efektivitasnya baik, tanpa efek samping, mudah dilakukan dan murah serta dapat dilakukan dimana saja.

\section{Efektivitas Pursed Lip Breathing dan Meniup Balon}

Semua penelitian yang ada dalam kriteria inklusi melaporkan hasil positif tentang penggunaan terapi pursed lip breathing dan meniup balon. Semua studi yang masuk dalam kriteria inkulusi ini hanya untuk memastikan efek intervensi, seperti peningkatan kekuatan otot pernapasan, respiratory rate, dan saturasi oskigen responden PPOK ataupun perokok usia muda. Secara umum untuk mengidentifikasi perubahan fungsi paru setelah intervensi. Studi Kim Jin-Seop (2012) \& Adib-Hajbaghery Mohsen (2011) melaporkan potensi keuntungan dari penggunaan terapi rehabilitasi ini untuk meningkatkan kesehatan dan memperbaiki pola hidup pasien PPOK, hal ini diteliti dalam uji klinis acak, dan studi memiliki kekuatan efisen untuk mendeteksi perubahan atau efek. Dalam studi tersebut kelompok kontrol tidak melaporkan efek yang lebih baik dari kelompok perlakuan pada penggunaan intervensi ini, hal ini bisa diliat pada deteksi dini perubahan klinis yang relevan, dibandingkan dengan perawatan rutin diberikan kepada kelompok kontrol. Studi Jingjuan $\mathrm{Xu}$ (2017) melaporkan biaya diperkirakan lebih rendah dari perawatan selama periode pemantauan 3 bulan, hari sakit lebih sedikit, 3 studi ini memiliki ukuran sampel yang kecil.

\section{DISKUSI}

Tinjauan sistematis ini memberikan gambaran yang komprehensif tentang efektvitas pursed lip breathing dan meniup balon terhadap kekuatan otot pernapasan, respiraty rate dan saturasi oksigen. 


\section{a. Efektifitas pursed lip breathing terhadap kekuatan otot pernapasan, saturasi oksigen dan respiratory rate}

Menurut Sherwood (2014) PPOK adalah sekelompok penyakit paru yang ditandai dengan peningkatan resistensi saluran napas yang terjadi akibat penyempitan lumen saluran pernapasan bawah. Pada pasien PPOK dapat terjadi pula hipoksemia dan hiperkapnia yang disebabkan karena terjadinya kelemahan otot pernapasan dan obstruksi maka dari hal itu akan terjadi peningkatan resistensi aliran udara, hiperinflasi pulmoner dan ketidakseimbangan ventilasi dan perfusi. Manifestasi klinis yang diperlihatkan adalah sensasi dada sesak dan dyspnea sehingga dapat menyebabkan penurunan kadar saturasi oksigen, tentunya hal ini sangat membutuhkan penanganan medis yang serius (LeMone, Priscilia, et al, 2016).

Pursed Lip Breathing adalah pernapasan melalui bibir yang dapat membantu melatih otot pernapasan, memperlambat ekspirasi, mencegah kolaps jalan nafas kecil, dan mengontrol kecepatan serta kedalaman pernafasan (Brunner \& Suddarth, 2015). Latihan pursed lip breathing berguna untuk memperbaiki ventilasi dan meningkatkan kerja otot abdomen dan toraks (Khazanah, 2013). Teori tersebut sejalan dengan study yang dilakukan KyoChul Seo (2017) bahwa pursed lip breathing dapat meningkatkan tekanan di perut sehingga dapat menyebabkan kenaikan drastis ventilasi paru-paru yang telah berkurang dan meningkatkan motilitas luas dinding dada yang mengarah ke peningkatan aktivitas otot pernapasan. Hal ini terjadi karena latihan khusus untuk otot pernapasan pada pursed lip breathing akan mengakibatkan bertambahnya kemampuan ventilasi maksimum, mengurangi sesak nafas, sehingga memperbaiki kualitas hidup (Khazanah, 2013). Latihan pernapasan dengan pursed lip breathing exercise ini akan terjadi dua mekanisme yaitu inspirasi kuat dan ekspirasi kuat dan panjang. Ekspirasi yang kuat dan memanjang akan melibatkan kekuatan dari otot intraabdomen pun meningkat yang akan meningkatkan pula pergerakan diafragma keatas membuat rongga toraks semakin mengecil. Rongga toraks yang semakin mengecil ini menyebabkan tekanan intra alveolus semakin meningkat sehingga melebihi tekanan udara atmosfer. Kondisi tersebut akan menyebabkan udara mengalir keluar daru paru ke atmosfer. Ekspirasi yang dipaksa dan memanjang saat bernafas dengan pursed lip breathing exercise akan menurunkan resistensi pernafasan sehingga akan memperlancar udara yang dihirup atau dihembuskan. Ekspirasi yang dipaksa dan memanjang akan memeperlancar udara inspirasi dan ekspirasi sehingga mencegah terjadinya air trapping didalam alveolus (Khazanah, 2013).

Menurut studi yang dilakukan oleh Timothy Mickleborough, et al (2016), Jingjuan Xu, et al (2017) \& Margaret A. Nield, et al (2007) bahwa pursed lip brething dapat menurunkan sesak napas, menurunkan kejadian dispnea saat beraktifitas dan meningkatkan fungsi latihan. maka dengan hal ini dapat meningkatkan saturasi oksigen. Sedangkan studi yang dilakukan oleh Brian L. Tiep, et al (1986) bahwa setelah dilakukan latihan pursed lip breathing pada 12 orang hipoksemia PPOK kelompok intrevensi saturasi oksigen arteri meningkat dan dispnea semakin berkurang.

b. Efektifitas meniup balon terhadap kekuatan otot pernapasan, saturasi oksigen dan respiratory rate

Pasien PPOK pada umumnya mengalami peningkatan frekuensi pernapasan dengan ekspirasi 
memanjang, sebagai kompensasi dari sesak napas, biasanya otot-otot asesoris pernapasan bagian dada atas digunakan secara eksesif untuk membantu pergerakan dada. Otot-otot ini tidak dapat digunakan dalam jangka waktu lama sehingga fungsi ventilasi paru mengalami penurunan. Meniup balon secara rutin 10-15 balon dapat meningkatkan kapasitas paru, meningkatkan otot pernapasan (Raju, 2015). Hal ini sejalan dengan Study yang dilakukan oleh Das Smita Manjusha, et al (2018) bahwa sebelum dilakukan intervensi meniup balon, responden memiliki suara napas yang abnormal dan nampak menggunakan otot aksesori pernapasan saat bernapas dan batuk, namun setelah enam hari melakukan intervensi ini nampak tidak terdengar lagi suaran napas yang abnormal pada responden dan tidak nampak lagi penggunaan otot aksesori saat bernapas. Secara empiris bahwa teori dari Raju tidak ada perbedaan dari hasil studi yang dilakukan oleh Manjusha Das. Studi dari Manjusha Das pula diperkuat pula oleh Boyle (2010) bahwa pernapasan dengan meniup balon dapat meningkatkan otot neuromuskuler dan saraf parasimpatis menjadi rileks atau dapat menurunkan tonus otot. Latihan ini dapat menyeimbangkan tekanan intra abdominal selama inhalsi.

Balloon blowing atau latihan pernapasan dengan meniup balon merupakan salah satu latihan relaksasi pernapasan dengan menghirup udara melalui hidung dan mengeluarkan udara melalui mulut kedalam balon. Relaksasi ini dapat memperbaiki transport oksigen, membantu pasien untuk memperpanjang ekshalasi dan untuk pengembangan paru yang optimal (Jun Jun H, 2015). Hal ini juga dibuktikan oleh studi Manjusha Das (2018) bahwa intervensi meniup balon dapat memperbaiki saturasi oksigen jika dilihat dari nilai klinis pasien, hal ini dapat dilihat dari bahwa responden diawal test saturasi oksigennya rata-rata 93,77 $\pm 1,83$ sedangkan pada akhir testnya rata-rata $97,9 \pm 1,57$. Studi tersebut diperkuat pula oleh Tunik (2017) bahwa pemberian breathing relaxation dengan teknik meniup balon dapat mempengaruhi saturasi oksigen dan perubahan fisiologis kecemasan.

Studi yang dilakukan oleh Kim Jin Seop, et al (2012) dari 15 responden sebagai kelompok kontrol yang diberikan intervensi meniup balon selama delapan minggu dapat meningkatkan VC, ERV, Irv, FVC, FEV1, FEV1 / FVC dan PEF secara signifikan dibanding dengan kelompok kontrol yang tidak mengalami peningkatan. Semantara studi yang dilakukan Manjusha Das (2018) bahwa ada perbedaan yang signifikan pada laju respirasi pada responden, yaitu hasil pengukuran pretest rata-rata laju respirasi $(29,47 \pm 4,47)$ posttest laju respirasinya $(19,53 \pm 2,32)$. Sedangkan studi yang dilkukan oleh Renuka, et al (2015) bahwa latihan meniup balon dapat memperbaiki status pernapasan pada kelompok kontrol yang diukur pada status pernafasan dalam hal tingkat pernapasan, skala dyspnea dan kapasitas paru-paru pada pasien dengan gangguan saluran pernapasan bagian bawah. Hal ini sejalan dengan teori Raju (2015) bahwa latihan meniup balon dapat mencegah terjadinya sesak napas dan kelemahan karena oksigen yang masuk dalam tubuh menyediakan energi untuk sel dan otot dengan mengeluarkan karbondioksida. Sedangkan menurut Kim, Jin S. (2012), bahwa meniup balon merupakan latihan yang memberikan kemampuan yang efektif bagi paru untuk melakukan pengambilan dan pengeluaran udara paru, selama latihan alveoli akan mengeluarkan karbondioksida yang terjebak dalam paru selama ekhalasi dan memasukkan oksigen dalam darah selama inhalasi.

\section{KESIMPULAN}


Untuk menghindari gangguan vital pada pasien PPOK akibat terganggunya pernapasan dan proses ventilasi maka dapat dilakukan dengan program latihan. Program latihan yang dapat dilakukan salah satunya yaitu dengan cara rehabilitasi yang terdiri atas pursed lip breathing dan meniup balon untuk meningkatkan kekuatan otot pernapasan, saturasi oksigen dan menurunkan frekuensi pernapasan. Pursed Lip Breathing adalah pernapasan melalui bibir yang dapat membantu melatih otot pernapasan, memperlambat ekspirasi, mencegah kolaps jalan nafas kecil, dan mengontrol kecepatan serta kedalaman pernafasan. Sedangkan Balloon blowing atau latihan pernapasan dengan meniup balon merupakan salah satu latihan relaksasi pernapasan dengan menghirup udara melalui hidung dan mengeluarkan udara melalui mulut kedalam balon, dengan meniup balon secara rutin balon dapat meningkatkan kapasitas paru, meningkatkan otot pernapasan, mempengaruhi saturasi oksigen, memperbaiki status pernapasan pasien PPOK.

\section{DAFTAR PUSTAKA}

American Lung Association (2015). Lung Disease. Tersedia: http://www.lung.org/lungdisease/influenza/in-depthresources/ pneumonia-fact-sheet.html. Diakses pada 1 Januari 2018 pukul 14.00 WIB.

Barnett, Margaret. (2017). Chronic Obstruktive Pulmonary Disease. Chichester : John Willey \& Sons, Ltd.

Boyle, K. (2010). The Value Of Blowing Up A Balloon. $N$ Am Jsports Phys Ther 2018 Sep ; 25 (30:179-188

Cabral, L. F., D'Elia, T. C., Marins, D. S., Zin, W. A., \& Guimarães, F. S. (2015). Pursed lip breathing improves exercise tolerance in COPD: a randomized crossover study. Eur $J$ Phys Rehabil Med, 51(1), 79-88.

Das, M. S. M., Nayak, M. G. R., \& Pradhan, M. R. (2018). Effect of Balloon Therapy vs. Bubble Therapy on LRTI among 3-12 Years Children. therapy, 18, 60.

Global Initiative for Chronic Obstructive Lung Disease (GOLD). (2016). Global Strategy for the Diagnosis Management and Prevention for Chronic Obstructive Pulmonary Disease

Global Initiative for Chronic Obstructive Lung Disease (GOLD). (2017).Global strategy for the diagnosis, management, and Prevention of chronic obstructive pulmonary disease (updated 2013). January 20, 2018. Global Initiative for Chronic Obstructive Lung Disease, Inc. www.goldcopd.org.

Izadi-avanji, A. F. S., \& Adib-hajbaghery, M. 2011. Effects of Pursed Lip Breathing on Ventilation and Activities of Daily Living in Patients with COPD Effects of Pursed Lip Breathing on Ventilation and Activities of Daily Living in Patients with COPD Abstrct, 2(4), 1-8.

Ju Jun, H., et al 2015. Comparison Of The Impact Or Breathing Strengthening Exercise And Balloon Blowing Training On The Pulmonary Function Of Elderly Smoker. Journal international academy of physical therapy research. 6 (2) 878-883

Khasanah, s., \& Maryoto, m. (2013). Efektifitas posisi condong ke depan (ckd) dan pursed lips breathing (plb) terhadap peningkatan saturasi oksigen pasien penyakit paru obstruktif kronik (PPOK). in prosiding seminar nasional \& internasional

Kim et al. (2012). Effects of breathing maneuver and sitting posture on muscle activity in inspiratory accessory muscles in patients withchronic obstructive pulmonary 
disease.

Respiratory

http://www content/7/1/9

Kim, Jin S. (2012). Effects Of Balloon-

Blowing Exercise On Lung Function

Of Young Adult Smokers. J. Phys.

Ther. Sci. 24: 531-534

LeMone, Priscilia, et al. (2016). Buku Ajar Keperawatan Medikal Bedah, Gangguan Respirasi. EGC : Jakarta

Mulyani, S. R. I., \& Muslima, E. (2018). Effectiveness of Pursed Lip Breathing To Changes Respiratory Rate In The Patients With COPD In Lung Room RSUD Dr R. Sosodoro Djatikoesomo Bojonegoro 2017. Jurnal Penelitian Kesehatan, 8(2).

Profil Kesehatan Sulawesi Selatan. (2017). Laporan Dinas Kesehatan Provinsi Sulawei Selatan 2018

Regional COPD Working Group. COPD. (2015). Prevalence in 12 AsiaPacifik Countries and Regions : Projections based on the COPD Prevalence estimations model. Respirologi : vol. 8: 192

Renuka, K., Helen Shaji, J. C., \& Kripa Angeline, A. (2015). Effectiveness of balloon therapy on respiratory status of patients with Lower Respiratory Tract Disorders. International Journal of Science and Research, 4(3), 496-500.

Riskesdas. (2013). Riset Kesehatan Dasar Tahun 2013, Kementerian Kesehatan Republik Indonesia, diakses pada tanggal 14 januari 2018 (http: www.depkes.go.id/resources/downlo ad.pdf)

Sachdeva, M., Shaphe, M. A., \& Mahajan, D. (2013). Comparison of Active Cycle Of Breathing Technique and Pursed Lip Breathing with Thera PEP $®$ in Patients with Acute exacerbation of COPD. International Journal of Physical Therapy

Research \& Practice., 1.

Smeltzer S. C., Bare G. B. (2013). Buku Ajar Keperawatan Medikal Bedah,
Edisi 8 Volume 1. Penerbit Buku Kedokteran EGC: Jakarta.

Thomsen, Lars. (2014). Measuring Gas Exchange With Step Changes In Inspired Oxygen: An Analysis Of The Assumption Of Oxygen Steady State In Patients Suffering From COPD. J Clin Monit Comput (2014) 28:547-558 DOI $10.1007 / \mathrm{s} 10877$ 014-9622-2

Tunik, T., Rosa, E. M., \& Khoiriyati, A. (2017, July). The Effectiveness of Breathing Relaxation with Ballon Blowing Technique toward Physiological Changes of COPD Patients. In ASEAN/Asian Academic Society International Conference Proceeding Series.

Volvato et al. (2015). Relaxation techniques for people with Chronic Obstructive Pulmonary Disease : A systematic Review and Meta Analysis. Artikel ID 628365, 22 pages 7 (11) : e49070

Williams, Dennis M, Bourdet, Sharya V. (2014). Chronic Obstruktive Pulmonary Diseas. In : DiPiro, J., et al ., (Eds). Pharmacotherapy A Patophysiologyc Aprroach Seventh Edition. New York : Mc Graw-Hill. pp. $528-550$.

Windrasmara, Oni Juniar. 2012. Kedokteran Klinis. Jakarta : Erlangga Xu, J., He, S., Han, Y., Pan, J., \& Cao, L. (2017). Effects of modified pulmonary rehabilitation on patients with moderate to severe chronic obstructive pulmonary disease: A randomized controlled trail. International Journal of Nursing Sciences, 4(3), 219-224. 